\title{
Research on the Effect of Awards and Grants to Improve the Ability of Scientific Research after 2014 in China
}

\author{
Qunhua Yuan ${ }^{1} \&$ Xiaoru Zhang ${ }^{1}$ \\ ${ }^{1}$ Guangdong University of Foreign Studies, GD, China \\ Correspondence: Xiaoru Zhang, Guangdong University of Foreign Studies, GD, China.
}

Received: May 27, 2020

doi:10.5539/hes.v10n3p88
Online Published: July 29, 2020

URL: https://doi.org/10.5539/hes.v10n3p88

\begin{abstract}
The National Graduate Education Comprehensive Fees Policy has been in operation for more than five years since the fall semester of 2014, which is long enough to evaluate the effectiveness of the policy. Base on the existing research results, this paper proposes to adopt the core index of graduate students' scientific research ability - the level and quantity of published papers to evaluate the implementation effect of this policy, take GF University as an example to analyze the construction of the university's award and scholarship system, and make quantitative analysis of the academic graduate students' published papers. It finds that the implementation effect of scholarship system is not obvious. Therefore, this paper analyzes the reasons and puts forward the relevant countermeasures.
\end{abstract}

Keywords: graduate education, awards and assistantships, evaluation, thesis Publishing

\section{Introduction}

The National Graduate Education Comprehensive Fees Policy (Note 1) was implemented in the national postgraduate education in the fall semester of 2014, six sessions of graduates have been awarded and subsidized in accordance with the new grant policy. The evaluation of the implementation effect of the policy has become one of the scholar research's focus. As expected, the implementation of the policy changes the funding policy of "one examination for three years", and enhances the enthusiasm for postgraduates to participate in academic research. Most of the existing research results have concluded that the reform of graduate awards and grants after the comprehensive charging policy plays a positive role in improving the enthusiasm of students' learning and research, but there are many shortcomings. In order to explore whether the construction of the system of awards and grants achieve its original purpose, this paper evaluates the effect after the implementation of the policy.

\section{A Brief Review of Literature}

Since the National Graduate Education Comprehensive Fees Policy was implemented in 2014, there have been many related policy evaluation paper studying the effect of this policy. Liu (2017) found that the scholarship reform achieves positive results and plays a positive role in ensuring students' lives and stimulating their enthusiasm for learning and scientific research, but there are also some problems. Xu (2018) conducted an investigation on the evaluation of national scholarships for postgraduates in 15 universities in Beijing in the recent three years, and found that the establishment of national scholarships plays a positive role in encouraging students to devote more energy to academic research, but there are still many areas to be improved. According to the survey of Peng (2019), the degree of achievement of the National Scholarship System Award goal for doctoral students in liberal arts is not obvious. There is no significant difference between the scientific research ability of doctoral students in liberal arts who have won the national scholarship and those who have not won the national scholarship. The study of Luo and Kuang (2019) show that the incentive effect of scholarship on postgraduate learning generally take effect, but the effect is different under the influence of various factors.

Most of the above literature are from the perspective of stimulating the learning enthusiasm of postgraduates, and a few are evaluated from the effect of motivation. These still have some limitations. First, promoting the enthusiasm of postgraduates in learning and scientific research does not really improve their academic level. Second, because most of these studies take the form of questionnaires and interviews, which are more subjective and arbitrary, reflecting the feelings of the respondents, the conclusions can not fully reflect the construction of graduate education after the full charge of the award and scholarship system and whether the implementation 
really achieves its goal.

Promoting scientific research ability is the core task of postgraduate education, and the level and quantity of published papers are the key indicators of scientific research ability of postgraduates. Therefore, this paper will take the published papers of graduate students as the evaluation indicators to investigate the construction and implementation effect of GF University graduate award system.

\section{The Construction of the Financial Scholarship System for the Economic Postgraduates in GF University}

\subsection{Types of Graduate Scholarships and Per Capita Funding}

Similar to most of China's university scholarship systems, GF University scholarships mainly include national scholarships, academic scholarships, excellent postgraduate freshman scholarships, graduate innovation awards, graduate overseas scholarships, etc. Assistantships include national scholarships, "three assistance and one assistance" subsidies, national student loans, special difficulties subsidies, graduate research and innovation new project funding, academic conference funding, study abroad funding, etc. According to the current grant standard, eligible doctoral students can receive at least 180,00 yuan and at most 50,000 yuan a year, and eligible postgraduates can receive at least 9,000 yuan and at most 31,000 yuan a year. Due to the proportion of awards and assistantships, the annual per capita subsidy for doctoral students is about 20,000 yuan, while about 13,000 yuan for master students . With the rising price level, except from 8,000 yuan tuition fee, the postgraduates should spend at least 15,000 yuan on other expenses, and totally at least 23,000 yuan per year, which is more than the annual per capita subsidy of 13,000 yuan. The tuition fees for doctors include two types, self-funded and public fees. The tuition fees for self-funded students are about 30,000 yuan per year, and the other living expenses are about 15,000 yuan, totaling 45,000 yuan, which is more than the annual per capita subsidy of 20,000 yuan. Therefore, the current amount of scholarships and awards for a considerable number of students (especially self-funded doctoral students) is not enough to cover the tuition and daily expenses, which is similar to the situation in foreign countries.

\subsection{The Structure of Funding Sources of Graduate Awards and Assistantships}

The main sources of graduate awards in China are government grants, school self financing, and social donations. In general, the government funding and school self financing account for a large proportion, while social donation and tutor assistance account for a relatively low proportion. Similarly, taking the awards and assistantships of GF Universities in 2019 as an example, according to the estimation of relevant data, the government grants account for $35.17 \%$ of the funding sources of graduate awards and assistantships, the school's self-raised funds account for $60.39 \%$, the donations of social enterprises account for only $0.88 \%$, and the tutors' grants to students from scientific research funds account for about 3.56\%, which is consistent with most universities in China. However, in developed countries, although the source of scholarships is also mainly dependent on the government, according to the 2000 edition of American scholarship, all kinds of American scholarships amount to $\$ 50$ billion, the federal government's scholarships account for $75 \%$ of the total amount of all scholarships, and the students who receive other financial support, such as social donations, account for about $30 \%$. Besides, statistics show that about $70 \%$ of the funding is from federal government loans. Therefore, considering the attribute of graduate education and the cost sharing mechanism, it is crucial to increase the degree of government financial aid and the proportion of social donations to change the source structure of graduate awards and grants in China.

\subsection{The Policy and Effect of GF University Graduate Awards and Grants to Promote Scientific Research Ability}

\subsubsection{GF University Graduate Scholarship Selection Standard Focuses on Academic Ability Improvement}

From the perspective of the national scholarship and academic scholarship documents of GF Universities, the selection criteria are more focused on the level of scientific research achievements. For example, in addition to meeting the requirements of academic achievements and basic scientific research achievements, it emphasizes that "those who publish high-level academic papers in academic journals with greater influence in this discipline or in this field are preferred". While in the same level of achievements, the quantitative advantage is more competitive. On the whole, the evaluation methods of all kinds of scholarships are aimed at improving the scientific research ability of postgraduates. The grant standard of the university is more focused on the students' economic ability, mainly to ensure that they can maintain the basic study and life in school.

\subsubsection{Statistical Analysis of Papers Published by Economic Academic Postgraduates in GF University}

In order to analyze the level and quantity of postgraduates' published papers, this paper uses the per capita published papers at graduation as indicators, the total number of papers published per capita, the number of CSSCI papers published per capita, and the number of papers published per capita in common core journals 
(including all kinds of blue books). Besides, in order to reflect the contribution of postgraduates, only the papers of students as the first and second authors (tutor is the first author) are included. Since the comprehensive charge policy for postgraduate education was implemented in 2014, and the graduate program is a three-year system, the first students affected by the policy are the class of 2017. Therefore, this paper takes the former and the latter three classes of graduates as the comparative reference system.

The statistical results show that from 2014 to 2019, the number of papers published by the economic academic postgraduates from GF Universities show a trend of rapid growth and then rapid decline. The total number of papers published per capita increased from 1.19 in 2014 to a peak of 1.94 in 2017, and then decreased to 1.21 in 2019. Among them, the number of CSSCI journal papers per capita also fluctuated greatly, with two peaks respectively appearing in 0.21 in 2015 and 0.25 in 2018. The number of general journal papers per capita is consistent with the trend of the total number of papers per capita, which is also a rapid growth followed by a rapid decline, but the peak was 1.76 in the class of 2016.

Table 1 Statistical Analysis of papers published by economic academic postgraduates in GF University

\begin{tabular}{llll}
\hline Graduation Year & $\begin{array}{l}\text { Total articles } \\
\text { per capita }\end{array}$ & $\begin{array}{l}\text { Number of CSSCI journal } \\
\text { papers per capita }\end{array}$ & $\begin{array}{l}\text { Number of ordinary journal } \\
\text { papers per capita }\end{array}$ \\
\hline 2014 & 1.19 & 0.15 & 1.05 \\
2015 & 1.26 & 0.21 & 1.23 \\
2016 & 1.35 & 0.12 & 1.76 \\
2017 & 1.94 & 0.18 & 1.28 \\
2018 & 1.53 & 0.25 & 1.11 \\
2019 & 1.21 & 0.11 & 1.04 \\
\hline
\end{tabular}

Note: data comes from actual work statistics.

From the above statistical analysis results, the construction of GF University Graduate awards and assistantships system has basically achieved the purpose of graduate education fee reform, and improved the enthusiasm of graduate study and scientific research. However, judging from the number of published papers, it is not obvious that the postgraduate awards and grants can improve the research ability.

\subsection{An Analysis of the Reasons Why Graduate Grants Are Not Obvious In Improving Scientific Research Ability}

3.4.1 The Policy of Awarding and Assistantship is not Enough to Stimulate the Enthusiasm of Postgraduate Research

The common deficiency of the policy is that it is not significant to enhance the innovative achievements of scientific research in most colleges and universities in China. The reason lies in that the incentive function of the scholarship not only depends on the setting of evaluation conditions, but also on the enthusiasm of the graduate students themselves for scientific research. For most graduate students, the purpose of their postgraduate study is not to improve their scientific research ability, but to prepare for finding a good job by getting a higher level diploma, or indulge in various certificates and internships during postgraduate study. Although it's reasonable for graduate students to prepare for employment during postgraduate study, many students reverse their priorities and fail to see the improvement of the ability to analyze and solve problems. To sum up, the uncertainty of the short-term and long-term benefits of graduate students in the process of postgraduate study leads to their participation in scientific research. In practice, since the implementation of the national scholarship, it dose not play a very significant role in promoting the enthusiasm of scientific research.

3.4.2 There is A Guiding error in Using the Comprehensive Test Score as the Standard of Scholarship Evaluation

Comprehensive score is to measure and assign a certain weight to academic achievements, scientific research achievements, participation activities and other references in the form of scores, so as to obtain a comprehensive test score. This kind of evaluation standard seems reasonable and comprehensive, but in practice, students with general academic achievements and scientific research achievements often get high-level scholarships. The reason is that these students hold certain positions of student cadres, they are ahead of other students in the comprehensive evaluation. This approach reduces the proportion of scientific research and academic achievements. In view of the guiding role of scholarships, the comprehensive examination score as the criteria for scholarship evaluation affects the orientation of innovation ability training.

3.4.3 The Academic Level of Mentors Is Limited and the Investment of Mentors Is Insufficient

The academic level and guidance input of tutors are also the key to the improvement of graduate students' 
scientific research ability. As the first person of postgraduates' ideological understanding and academic guidance, tutors play an important role in the improvement of postgraduates' academic knowledge and academic literacy. However, in practice, we found that due to the lack of scientific research literacy, theoretical basis and research methods of some tutors, they could not give correct academic guidance, leading to a lack of guidance from tutors for some graduate students. Therefore, it is necessary to screen the tutor's guidance qualification according to the guidance ability and increase the corresponding reward and punishment to promote the students' scientific research ability and academic level.

\subsection{The Measures to Improve the Ability of Scientific Research Innovation of Postgraduates in China}

In order to achieve the above goal of improving the scientific research and innovation ability of postgraduates in China, according to the current financial situation and the implementation of university grants, this paper puts forward the path of the construction of graduate student grants system in China. First, government should increase the scale and intensity of government student loans to make it account for more than half of the entire funding system, and better stimulate their enthusiasm in scientific research. Second, universities and colleges should strengthen the degree of postgraduates' participation in the research and obtain corresponding rewards in the process, and change the reward of results into process cultivation. In order to avoid the randomness of graduate students to obtain funding after participating in project research, it is imperative to establish corresponding management methods for project funding, such as setting up special graduate research projects. The specific approaches are as follows.

(1) Enhance the ideological understanding of postgraduates for academic. Promoting ideological understanding is the basis for the smooth development of the work. Only when the graduate students have a good understanding of the academic thought, they can guarantee their lasting enthusiasm for scientific research. In the daily work of postgraduates, it is found that the enthusiasm of some postgraduates is not high, and the purpose of their postgraduate study is to get a better job. Therefore, it is necessary to strengthen their ideological construction, improve their understanding of academic research, and make them realize that doing academic research is conducive to improving their thinking ability. Academic thinking is working thinking, scientific research ability is also the basis of working ability in the future, which is conducive to the development of students in the long run.

(2) Encourage postgraduates to participate in tutor research. Project research is the basis and way to cultivate research ability. It includes not only experiment, project writing, but also field investigation and academic exchange. Tutors may provide support from their project funds to cultivate their innovation ability. For example, a considerable part of the grants for postgraduates in Europe and the United States come from the project funds of the tutor, which requires postgraduates to participate in the tutor's project and complete some corresponding tasks. In addition, whether the tutor can obtain scientific research funds is also one of the important indicators to measure the academic ability of the tutor, so as to achieve the survival of the fittest.

(3) Set up special projects combined with national talent demand. In the system of graduate awards and assistantships, there should be not only awards and assistantships for all postgraduates, but also special talent funding programs. Government should set up a special competitive project on the national talent demand to give university funds, including the establishment of talent plans, which can better serve the national strategy, and meet the needs of the country for special talents.

(4) Improve the scholarship system and rationalize the funding system. After obtaining sufficient sources of funds, management and distributions of these funds are very important, which involves donor recognition and sustainable development. Therefore, it is necessary to improve the system of award and assistantship, refine it as much as possible under the condition of realizing the purpose of the award and assistantship. Facilitating the operation, and preventing moral hazard or selection deviation are also of great importance. In the scholarship system, there should be not only financial arrangements for all students (such as general scholarships and poverty subsidies, if they meet the requirements), but also competitive financial arrangements (mainly scholarships). In the distribution of graduate awards and assistantships, special attention should be paid to avoid the situation that some excellent students get all the basic highest level awards and assistantships, which requires the corresponding provisions in the design of the award and assistantships system.

(5) Improve the management organization. Any system must rely on people to implement, so it is necessary to set up a special management organization to manage the scholarship. The establishment of a special organization to manage the grant have some benefits. First, it is conducive to raising funds, having an interface with funds, and facilitating development. Second, it is conducive to the formulation and implementation of the system. During implementation, the special management organization continuously adjusts the relevant system according 
to the actual situation and goals. Third, the responsibilities and rights are clear. Any problems that occur during the formulation of the scholarship system and the evaluation of the scholarships can well clarify the responsibilities and achieve the matching of responsibilities and powers.

\section{Conclusion}

According to the published papers and the implementation effect, the effect of graduate awards and grants on improving scientific research ability is not obvious. The main reasons are as follows. First, the scholarship policy has not stimulated the enthusiasm of postgraduates in scientific research. Second, there is a guiding error in using the comprehensive evaluation score as the standard for scholarship evaluation. Third, the academic level of the tutor is limited and the investment in guidance is insufficient. Based on the above conclusions, the policy suggestions are put forward from various aspects such as enhancing postgraduates' understanding of academic ideas, encouraging them to participate in the research of mentor projects, setting up special projects combined with the needs of national talents, improving the scholarship system and scholarship management institutions.

\section{Recommendation for Future Research}

Different from the previous questionnaire survey, this paper analyzes the results to explore whether the construction of graduate incentive system has achieved the expected purpose. The weakness of this study is that the sample is single, only from the representative cases to draw conclusions. Due to the limitation and availability of real data, this paper does not obtain large-scale data from colleges and universities across the country, adopt large sample statistical analysis and draw more convincing conclusions. Therefore, the authors courage future researcher to get more samples and use further statistical methods to get more reliable conclusions. Besides, the reform of the system of graduate awards and assistantships is helpful to enhance the enthusiasm of postgraduates for academic research. To improve the scientific research ability and academic level of postgraduates, future researcher need to start from many aspects, such as from the perspective of ideological understanding and mentoring investment.

\section{Project Support}

Guangdong undergraduate innovation and entrepreneurship education reform research project "Guangdong Foreign Economic and Trade Innovation Talents Training Research under the open economic pattern", 2018a052144, Department of education of Guangdong Province.

\section{References}

Akombo, D. O. (2013). Scholarship and Diversity in Higher Education. Journal of Cultural Diversity, 4(1), 3-6.

Liu, X. (2018). Research on the effect of the implementation of the academic scholarship system for master's degree students in Local Universities - Taking University A as an example. Master's thesis of Qingdao University.

Luo, J. G., \& Kuang, Y. P. (2019). Analysis of incentive effect and influencing factors of Graduate Scholarship -Based on the investigation of three "double first-class" universities in the foot of Yuelu Mountain. Broad vision, 04, 15-22.

Peng, Y. (2019). Research on performance evaluation of national scholarship system for doctoral students in arts. Master's thesis of Southwest University.

Wilkinson, A. C. (2011).Postgraduate Supervision as an Advanced Teaching and Learning Practice: Exploring the Scholarship Link. South African Journal of Higher Education, 19(2), 902-920.

Xu, W., LV, J. H., \& Pang, Y. X. (2018). Research and Analysis on the implementation and effect of national scholarship for graduate students - Taking 15 universities in Beijing as an example. Beijing Education (Higher Education), 12, 24-26.

Yuan, Q. H., \& Zhi, Z. P. (2014). Research on the construction of award and bursary system under the situation of comprehensive charge for Graduate Education - Based on the experience and lessons of European and American graduate education funding system. Cultural and educational materials, 24, 83-8.

\section{Notes}

Note 1. Before the comprehensive charging policy for graduate education was implemented, the charging policy was first piloted in Harbin Institute of Technology, Xi 'an Jiaotong University and Huazhong University of Science and Technology in 2006, and increased to 53 in 2008. But other colleges and universities still implement the public expense student and the self-fund student charge system. 


\section{Copyrights}

Copyright for this article is retained by the author(s), with first publication rights granted to the journal.

This is an open-access article distributed under the terms and conditions of the Creative Commons Attribution license (http://creativecommons.org/licenses/by/4.0/). 